Bolm Inst. oceanogr., S Paulo, 25:101-112, 1976

\title{
DISTRIBUIC,ÃO DE CLADOCORA DEBILIS METH, 1849 (FAVIIDAE, ANTHOZOA, CNIDARIA, AO SUL DO CABO FRIO $\left(23^{\circ} \mathrm{S}\right)$
}

\author{
CLEUZA FERREIRA LEITE ${ }^{1}$ \& LUIZ ROBERTO TOMMASI \\ Instituto Oceanográfico da Universidade de São Paulo
}

\section{SYNOPS IS}

The distribution of Cladocora debilis Meth in the region between Cabo Frio $\left(23^{\circ} \mathrm{S}\right)$ and Rio Grande do Sul $\left(34^{\circ} 35^{\prime} \mathrm{S}\right)$ is discussed. Its bathymetric distribution in that region is of 46 to 338 meters. It is one of the most conspicuous species of the circalitoral of the subtropical region of Brazil.

\section{INTRODUÇÃO}

A região ao sul do Cabo Frio apresenta um fundo circalitoral similar ao descrito por Pérès (1967) para o Mediterrâneo e por Longhurst (1958) para a costa ocidental africana (Tommasi, 1970). Alí ocorre uma rica região bêntica com corais ahermatípicos, inicialmente coletados pelo U.S. "Hessler" ao largo do Cabo Frio $\left(23^{\circ}\right.$ S) a $64 \mathrm{~m}$ de profundidade.

No presente trabalho procura-se analisar a distribuição de Cladocora debilis Meth na plataforma continental da região ao sul de Cabo Frio, em relação aos fatores ambientais estudados.

1 Estagiāria do Departamento de Oceanografia Biológica.

PUBL. NO 371 DO INST. OCEAN. DA USP. 


\section{MATERIAL E MÉTODOS}

Foram utilizadas amostras obtidas durante as viagens do N/Oc. "Prof. W. Besnard", para o desenvolvimento dos projetos "Recursos pesqueiros camaroeiros", "Macrobentos", "Oceanfauna" e "Programas Rio Grande do Sul I e II", bem como do N/Oc. "Almirante Saldanha", da Marinha do Brasil. Essas amostras foram coletadas, de 1968 a 1972, com dragas retangulares ou com traw1-deportas (Tab. I).

As amostras foram triadas preliminarmente a bordo e a triagem final foi realizada, posteriormente, em laboratório. 0 material foi todo fixado em á1cool 70\%. A Tabela I apresenta as posições de coleta, datas, natureza do fundo e demais dados das estações ocupadas, nas quais foram coletados exemplares de Cladocora. Como se trata de animal colonial é indicada a quantidade de exemplares por meio de uma convenção. Quando viva, a espécie apresenta coloração rosa claro.

Foram efetuadas análises de correlação simples e múltipla, utilizando-se para isso um computador 01ivetti Programa 101, bem como os programas 135 (correlação múltipla) e 1 b (coeficiente de correlação), ambos da 01ivetti.

\section{OCORRÊNCIA E DISTRIBUIÇÃO BATIMÉTRICA}

Foram obtidas amostras de Cladocora, desde $23^{\circ} 23^{\prime} \mathrm{S}-43^{\circ} 10^{\prime} \mathrm{W}$ até $34^{\circ} 35^{\prime} \mathrm{S}-51^{\circ} 56^{\prime} \mathrm{W}$, de 46 a $338 \mathrm{~m}$ de profundidade. Em uma amostra colhida a $1.140 \mathrm{~m}$, foram obtidos exemplares mortos. Essa amostra, dada a grande diferença de profundidade das demais e pela possibilidade de que exemplares tenham sido arrastados por correntes para tal região, não foi considerada no presente trabalho. Em todo caso, esta é a maior profundidade em que se coletaram, até o presente, exemplares desta espécie. A Figura 1 apresenta apenas a posição das estações realizadas em toda ārea nas quais foram obtidas amostras destes corais. Apesar de, na ärea entre $25^{\circ} \mathrm{S}$ e $28^{\circ} \mathrm{S}$, terem sido realizadas menos estações do que naquelas ao norte e ao sul dessas latitudes, é significativa a ausência desses corais nas amostras bênticas dessa região. 
TABELA I - Dados das estações nas quais foram obtidos exemplares de Cladocora debilis Meth

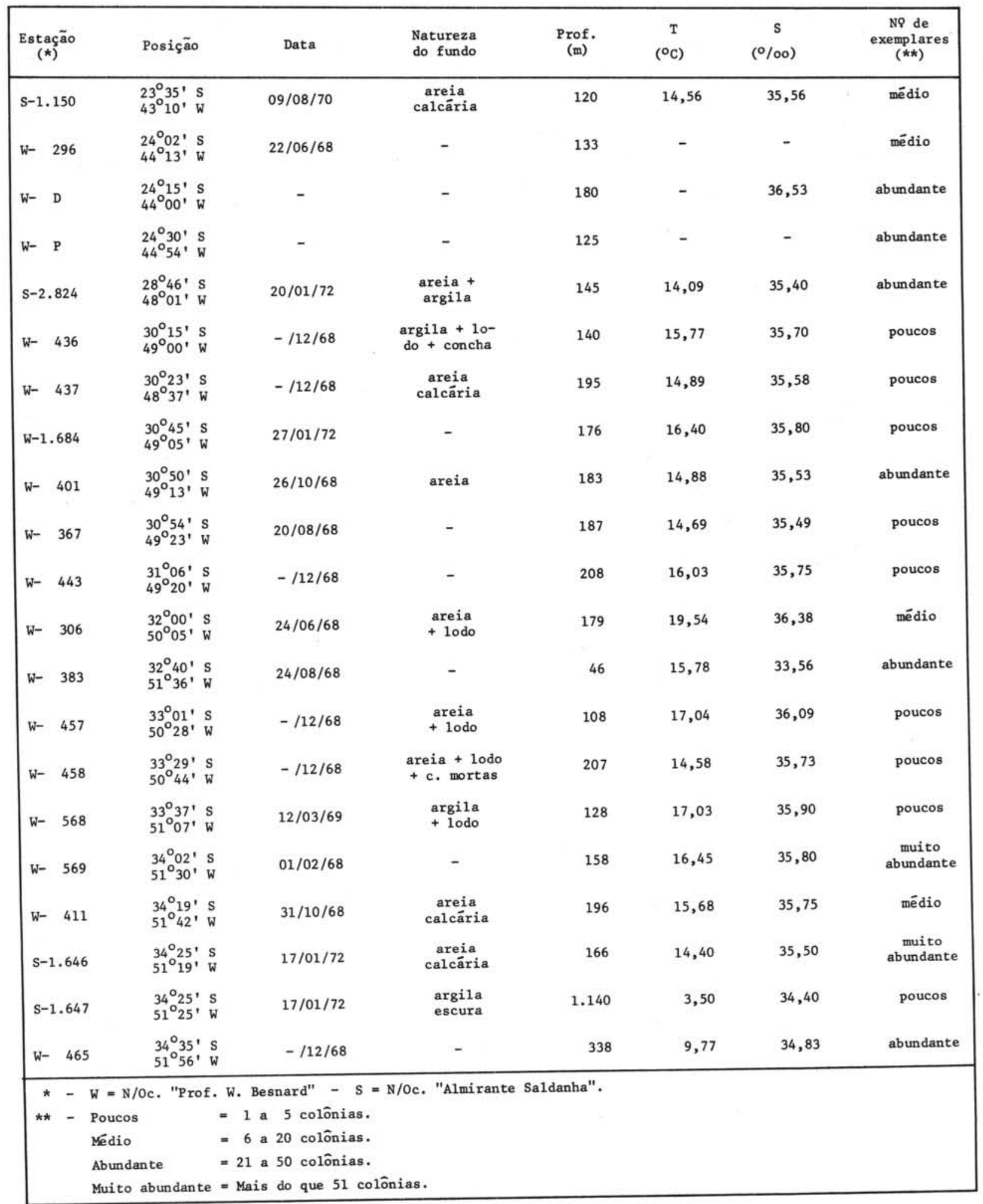




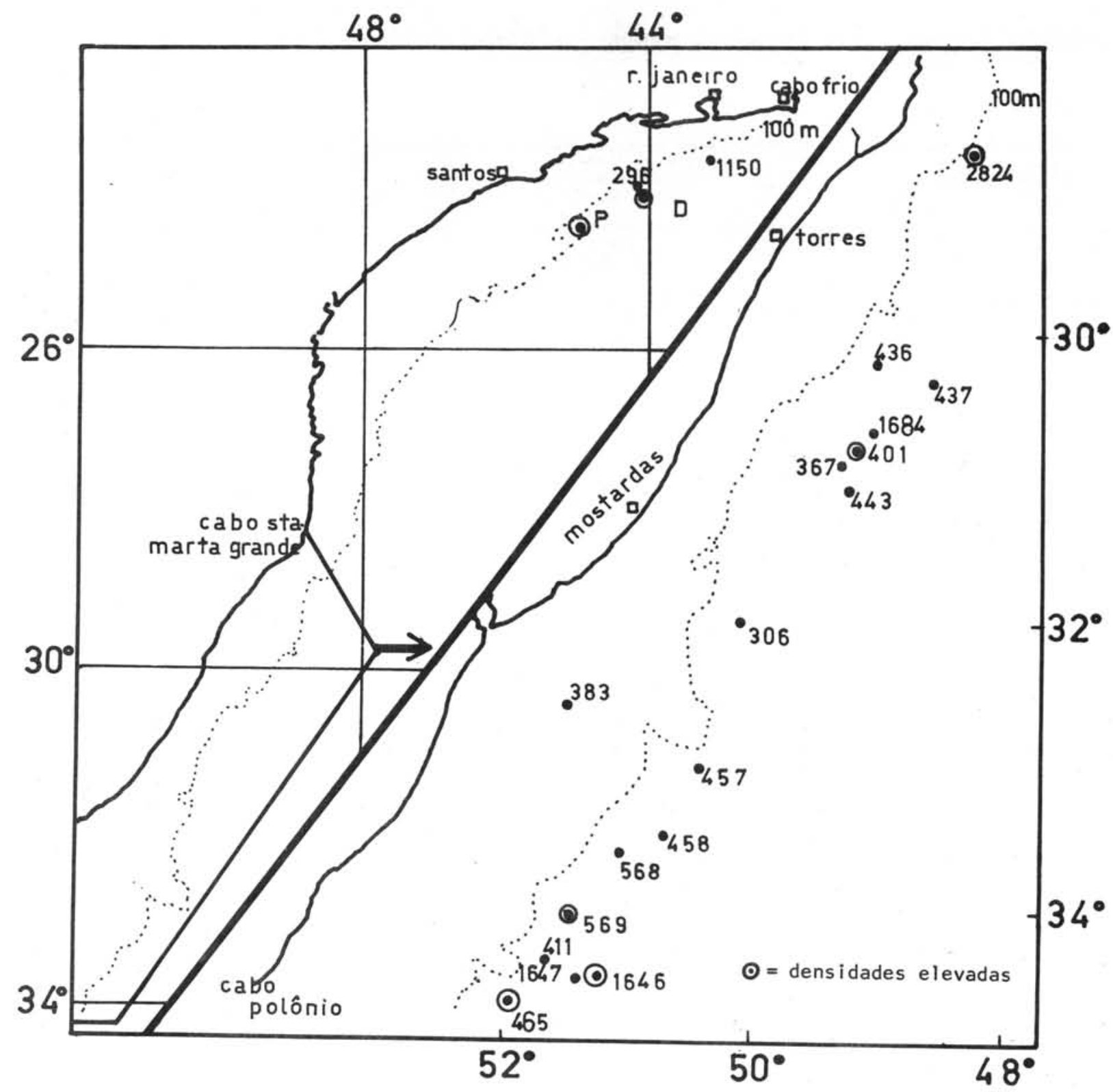

Fig. 1 -Posição das estações onde foram obtidas amostras de Cladocora debilis.

Isto sugere que, nessa região, ocorra uma forte redução dos bancos coralígenos, descritos por Tommasi (op. cit.), do circalitoral inferior. Por outro lado, foi na plataforma continental do Rio Grande do Sul que houve uma maior ocorrência desta espécie. Pôde-se, porém, verificar uma forte redução da ocorrência de Cladocora na zona entre $31^{\circ} 10^{\prime} \mathrm{S}$ e $32^{\circ} 50^{\prime} \mathrm{S}$. E interessante assinalar que é exatamente nessa região que registramos a ocorrência deste antozoário em menor profundidade, ou seja, $46 \mathrm{~m}$ (estação 383). 
A Tabela II apresenta a freqüência de ocorrência, em diversos intervalos de profundidade, mostrando que Cladocora ocorreu principalmente na faixa entre 151 e $200 \mathrm{~m}$ de profundidade, ou seja, no bordo inferior da plataforma continental.

TABELA II - Freqüência de ocorrência nas profundidades em que foram coletados exemplares de Cladocora debilis

\begin{tabular}{|ccc|}
\hline $\begin{array}{c}\text { Intervalo de } \\
\text { profundidade } \\
(\mathrm{m})\end{array}$ & No de estações & $\begin{array}{c}\text { Estações em que } \\
\text { ocorreu Cradocora } \\
(\%)\end{array}$ \\
\hline $0-50$ & 1 & 5 \\
$51-100$ & 0 & - \\
$101-150$ & 7 & 45 \\
$151-200$ & 9 & 10 \\
$201-250$ & 2 & - \\
$251-300$ & 0 & 5 \\
$301-350$ & 1 &
\end{tabular}

\section{DISTRIBUIÇÃO EM RELAÇÃO À TEMPERATURA, SALINIDADE E AO TIPO DE FUNDO}

A presente espécie ocorreu em água de fundo com temperaturas variando de 09,77 a $19,54^{\circ} \mathrm{C}$ e salinidades de 33,56 a $36,53 \%$. Verifica-se das Tabelas III e IV que houve nítida preferência por água com temperaturas entre 13,00 e $17,00^{\circ} \mathrm{C}$ e salinidades entre 35,51 e 36,00 \% $\%$. Na Tabela V verifica-se que houve nítida preferência por fundos de granulometria maior, ainda que tenha ocorrido em sedimentos bem diversos. 
TABELA III - Freqüência de ocorrência nos intervalos de temperatura em que foram coletados exemplares de Cladocora debilis

\begin{tabular}{|ccc|}
\hline $\begin{array}{c}\text { Intervalo de } \\
\text { temperatura } \\
\left({ }^{\circ} \mathrm{C}\right)\end{array}$ & No de estações & $\begin{array}{c}\text { Estações em que } \\
\text { ocorreu Cradocora } \\
(\%)\end{array}$ \\
\hline $9,00-11,00$ & 1 & 5,88 \\
$11,01-13,00$ & 0 & - \\
$13,01-15,00$ & 7 & 41,16 \\
$15,01-17,00$ & 6 & 35,28 \\
$17,01-19,00$ & 2 & 11,76 \\
$19,01-21,00$ & 1 & 5,88 \\
\hline
\end{tabular}

TABELA IV - Freqüência de ocorrência nos intervalos de salinidade em que foram coletados exemplares de Cladocora debilis

\begin{tabular}{|ccc|}
\hline $\begin{array}{c}\text { Intervalo de } \\
\text { salinidade } \\
(\% / 00)\end{array}$ & No de estações & $\begin{array}{c}\text { Estaçóes em que } \\
\text { ocorreu Cladocora } \\
(\%)\end{array}$ \\
\hline $33,51-34,00$ & 1 & 5,55 \\
$34,01-34,50$ & 0 & - \\
$34,51-35,00$ & 1 & 5,55 \\
$35,01-35,50$ & 4 & 22,20 \\
$35,51-36,00$ & 9 & 49,95 \\
$36,01-36,50$ & 2 & 11,10 \\
$36,51-37,00$ & 1 & 5,55 \\
\hline
\end{tabular}


TABELA V - Tipos de sedimento em que ocorreu Cladocora debilis

\begin{tabular}{|ccc|}
\hline Tipo de sedimento & Nọ de estações & $\begin{array}{c}\text { Estaçóes em que } \\
\text { ocorreu Cladocora } \\
(\%)\end{array}$ \\
\hline Argila & 1 & 7,69 \\
Argila e lodo & 2 & 15,38 \\
Areia e lodo & 5 & 38,45 \\
Areia calcária & 1 & 7,69 \\
\hline
\end{tabular}

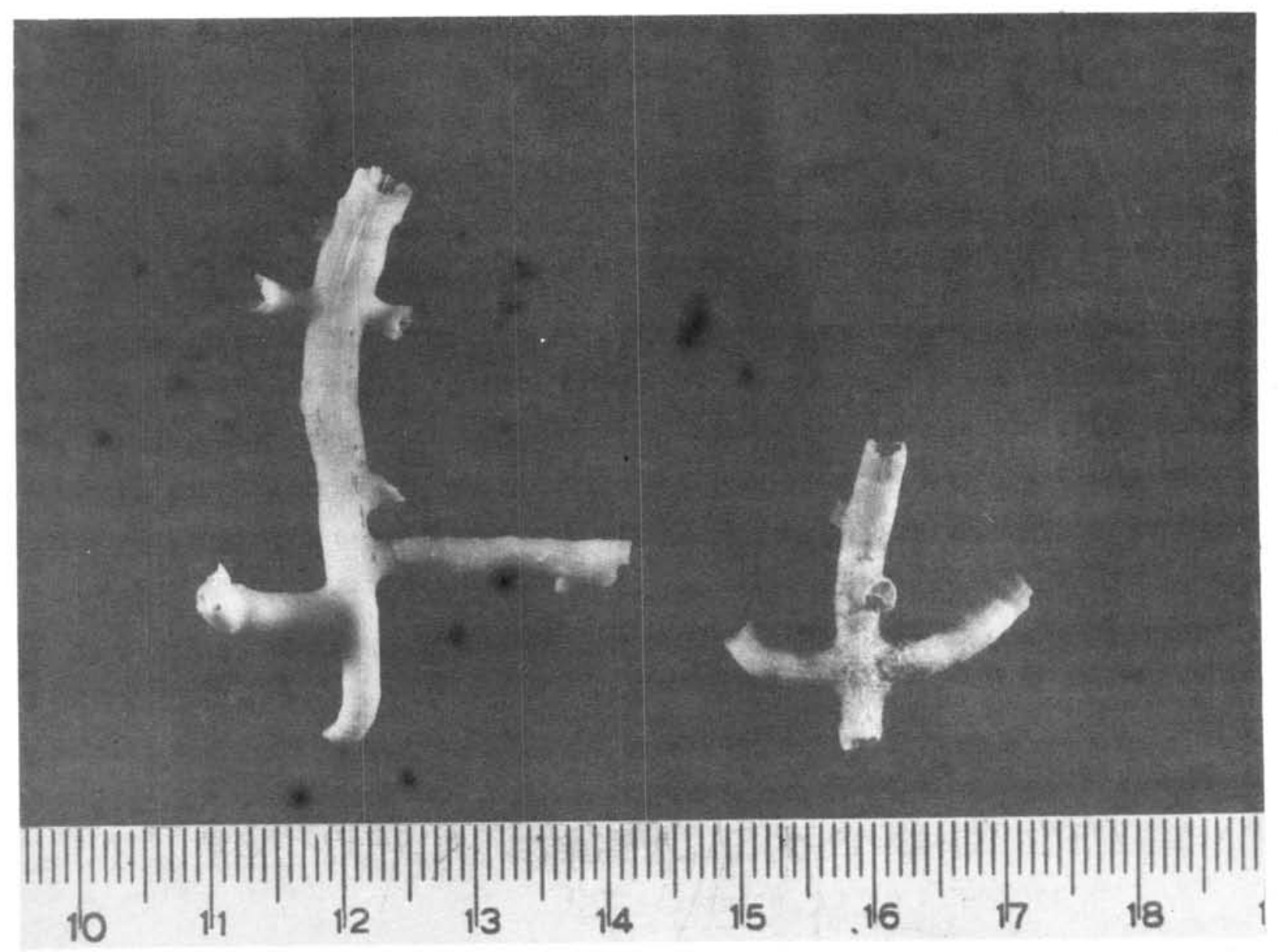

Fig. 2 - Vista geral de exemplares secos de Cladocora debilis Meth. 


\section{DISCUSSÃO}

As plânulas dos corais ahermatípicos fixam-se, somente, sobre substratos sólidos como rochas, corais mortos, restos de outros organismos calcários, grânulos maiores de areia, etc. Em geral, areia fina e lodo constituem substratos impróprios a estes animais. Não sobrevivem em ārea de pequena circulação de água e, conseqüentemente, de elevada taxa de sedimentação. A plataforma continental da região ao sul do Cabo Frio $\left(23^{\circ} \mathrm{s}\right)$, apresenta espessos depósitos terrígenos, relacionados com depósitos continentais e estuarinos.

Segundo Fairbridge (1966) è esse o tipo de plataforma de Sunda (Indonésia), região costeira do Golfo do México (Louisiana, Texas), região de grandes deltas como o do Orenoco, Amazonas, Reno, Huangho, Ganges, etc. Já a região ao norte de Cabo Frio, especialmente a do nordeste brasileiro (ver Kempf, 1970) seria plataforma similar a que ocorre no norte da Austrália, Yucatan, F1órida, Bahamas, etc.

Na plataforma ao sul do Cabo Frio atē a Ilha Grande, ocorrem ainda a1guns bancos calcários (Coutinho, 1970), mas, ao sul dessa ilha até o Rio Grande do Sul ela apresenta uma seqüência, da praia para o largo: areia, lodo-arenoso, areia, areia-calcária. Isso mostra que na região inferior dessa plataforma existem fortes correntes que determinam a existência daqueles fundos arenosos. Essa situação é a regra nas plataformas continentais e explica a existência de biocenoses coralinas ahermatîpicas naquela região.

Quanto à temperatura os corais ahermatípicos vivem desde cerca de $26^{\circ} \mathrm{C}$ atē $-1,1^{\circ} \mathrm{C}$; seu desenvolvimento máximo ocorre porēm entre 4,5 e $10^{\circ} \mathrm{C}$ (Wells, 1956). Resistem a salinidades de 27 a $40 \%$, mas são mais freqüentes em salinidade próxima de $36 \%$.

Segundo Pérès (1967) a intensidade luminosa do estāgio circalitoral è de 1 a $0,01 \%$ da incidente na superfície.

Os fundos do circalitoral onde ocorre Cladocora correspondem aos fundos detríticos da região inferior daquele estágio. Nessas regiões a biocenose ocorre em um fundo de sedimento misto, ou seja, de cascalho, areia e lodo. A 
fração de cascalho é essencialmente organógena. Essa situação é também a da região ao sul do Cabo Frio (ver Tommasi, 1970).

Esses fundos estão sujeitos a uma massa de água caracterizada por apresentar salinidades entre $35-36 \%$ e temperaturas entre 10 e $20^{\circ} \mathrm{C}$, a qual foi denominada por Emílsson (1961) de água de fundo da plataforma.

Exemplares de Cladocora debilis foram anteriormente assinalados na presente região por Pourtalés (1874, como C. patriarca) e por Tommasi (1970, como Cladocora arbuscula). Os presentes resultados mostram que ocorrem até a região ao largo do Cabo Polônio (Uruguai), mas, aparentemente, não ao sul dessa região. Amostras obtidas pelo N/Oc. "Almirante Saldanha" até à Província de Buenos Aires, mostram que daquela região para o sul ocorrem outros gêneros de corais como Flabellum, Desmophylum, Caryophyllia, Clavus, etc., mas não mais Cladocora, Desmomilia, Delthocyathus, Madracis, Trochocyathus, tão típicos da região ao sul de Cabo Frio (ver Gardiner, 1939 e Tommasi, 1970). Assim, na região do Uruguai, hã uma transição de uma fauna de corais ahermatípicos do circalitoral inferior da plataforma, que podemos denominar de subtropical, para uma tipicamente subantártica.

o coral Cladocora debilis é um dos mais conspícuos esclaractíneos ahermatípicos da região ao sul de Cabo Frio, formando em alguns locais, especialmente nos das estações 569 ( $\left.34^{\circ} 02^{\prime} \mathrm{s}-51^{\circ} 30^{\prime} \mathrm{W}, 158 \mathrm{~m}\right)$ e $1646\left(34^{\circ} 25^{\prime} \mathrm{S}-\right.$ $51^{\circ} 19^{\prime} \mathrm{W}, 166 \mathrm{~m}$ ) bancos muito ricos. Próximo a essas estações ocorrem outros locais também ricos, como o da estação 485. Mais ao norte, em frente à Solidão ocorre um novo fundo rico em Cladocora, ou seja da estação 401. Em seguida temos o da estação 2824, jā ao largo de Santa Catarina e finalmente novos fundos ricos apenas ao largo da Ilha de São Sebastião.

Apesar de que o número de amostras estudadas no presente trabalho tenha sido pequeno, a análise de correlação linear simples entre números de estações com Cladocora e temperatura, profundidade e salinidade, apresentou resultados não significativos, ou seja:

$\begin{array}{lccc} & \mathrm{r} & \mathrm{N} & \mathrm{P} \\ \text { Número de estações x temperatura } & 0.2541 & 7 & 0.5 \\ \text { Nümero de estações x salinidade } & 0.3947 & 4 & 0.5 \\ \text { Número de estações x profundidade } & 0.3678 & 6 & 0.5\end{array}$


Da mesma forma, análises de correlação linear múltipla mostraram ausência de significância entre os diversos fatores e número de estações com Cladocora, ou seja:

$\begin{array}{lcc} & \mathrm{r} & \mathrm{P} \\ \text { Nümero de estações x temperatura e salinidade } & 0.4513 & 0.5 \\ \text { Nümero de estações x temperatura e profundidade } & 0.3889 & 0.5 \\ \text { Nümero de estações x profundidade e salinidade } & 0.4603 & 0.5\end{array}$

Esses resultados podem sugerir que a ocorrência de Cladocora debilis seja devida a uma complexa interação de fatores ambientais inclusive outros, além dos estudados, e não a um ou dois combinados. Como acentuou Pérès (1967), os povoamentos bênticos circalitorais se diferenciam dos infralitorais por um aumento dos povoamentos de animais sésseis, em detrimento dos algais. Uma das principais características do circalitoral é a presença de concreções produzidas por organismos secretores de calcário, tanto animais como vegetais. Essas concreções permitem a formação de um substrato duro, a partir de um mole, passando assim a oferecer um excelente substrato à fixação de animais e de vegetais sésseis, bem como criando reentrâncias e superfícies diversas a espécies vägeis. Desenvolvem-se então nesses fundos as denominadas biocenoses coralígenas, das quais, Cladocora debilis é, na região ao sul de Cabo Frio, um dos elementos mais conspícuos. A presença de correntes no bordo da plataforma, determinando condições especiais de sedimentação; a profundidade, a baixa intensidade luminosa, condições de baixa temperatura e de salinidade elevada, ausência da influência das vagas e ondas, constituem os fatores que, integrados, determinam, basicamente, as condições ambientais nas quais ocorre este coral.

\section{RESUMO}

E analisada a distribuição de Cladocora debilis Meth na região ao sul do Cabo Frio $\left(23^{\circ} \mathrm{S}\right)$. Essa espécie ocorre até a região do Cabo Polônio (Uruguai), mas, aparentemente, não mais ao sul, onde esse gênero é ecologicamen- 
te substituido, juntamente com outros subtropicais, por espécies subantārticas. Ocorre de 46 a $338 \mathrm{~m}$ de profundidade, em água de fundo da plataforma, com temperaturas de 9,77 a $19,54^{\circ} \mathrm{C}$ e salinidades de 33,56 a $36,53 \%$. Foi mais freqüente entre 101 e $200 \mathrm{~m}$ e em regiões cuja água de fundo apresenta temperaturas de $13-15^{\circ} \mathrm{C}$ e salinidades de $35,51-36,00 \%$. Ocorre especialmente em fundos de granulometria maior e detríticos calcários. E uma das mais conspícuas espécies de corais ahermatípicos do circalitoral inferior da região entre o Cabo Frio $\left(23^{\circ} \mathrm{S}\right)$ e o Cabo Polônio ( $34^{\circ} 25^{\prime} \mathrm{S}$ ).

\section{SUMMARY}

Cladocora debilis Meth (=C. patriarca) occurs in depths between 46 and $338 \mathrm{~m}$, in temperatures of 9.77 to $19.54^{\circ} \mathrm{C}$ and salinities of 33.56 to $36.53 \%$. It is more abundant between $101-200 \mathrm{~m}$ and in detrital sandy bottons. It is one of most conspicuous ahermatipic corals of the subtropical region of Brazil.

\section{AGRADECIMENTOS}

Ao Dr. Stephen Cairms da Universidade de Miami, nossos agradecimentos por suas informações sobre a sinonímia de Cladocora debilis Meth. $\bar{A}$ Da. Lucy Teixeira pela revisão do manuscrito.

\section{B IBLIOGRAF IA}

COUTINHO, P. M. 1970. Preliminary investigations of the sediments between Cabo Frio and San Sebastião Island. Trabhs oceanogr. Univ. fed. Pernambuco, $9(10): 51-66$.

EMILSSON, I. 1961. The shelf and coastal waters off southern Brazil. Bolm Inst. oceanogr., S Paulo, 11(2):101-112. 
FAIRBRIDGE, R. W., ed. 1966. The encyclopedia of oceanography. New York, Reinhold, 1021 p.

GARDINER, J. S. 1939. Madreporarian corals, with an account of variation in CaryophyZlia. "Discovery" Rep., 18:323-338.

KEMPF, M. 1970. Notes on the benthic bionomy of the N. NE Brazilian shelf. Mar. Biol., 5(3):213-214.

LONGHURST, A. R. 1958. An ecological survey of the West African marine benthos. Fishery Publs colon. Off., (11):1-102.

PERES, J. M. 1967. Les biocoenoses benthiques dans le systeme phytal. Rec1 Trav. Stn mar. Endoume, (42):3-113.

POURTALES, L. F. de 1874. Zoological results of the Hessler Expedition, Crinoids and Corals. III. Cat1. Mus. comp. Zool., (8):27-52.

TOMMASI, L. R. 1970. Nota sobre os fundos detríticos do circalitoral inferior da plataforma continental brasileira ao sul do Cabo Frio (RJ). Bolm Inst. oceanogr., S Paulo, 18(1):55-62.

WELLS, J. W. 1956. Coelenterata - Anthozoa. Scleractinia. In: Moore, R.C., ed. - Treatise on invertebrate paleontology. New York, Geol. Soc. Amer., part F, p. 328-443. 